\title{
Elementary Student Knowledge Gains In The Digital Portable Planetarium
}

\author{
Laura D. Carsten-Conner, University of Alaska Fairbanks, USA \\ Angela M. Larson, The Goldstream Group, USA \\ Jennifer Arseneau, University of Alaska Museum of the North, USA \\ Robert R. Herrick, University of Alaska Fairbanks, USA
}

\begin{abstract}
Immersive environments hold promise to provide unique and heightened sensory experiences that focus a learner's attention, and thus may be useful learning platforms. In particular, portable planetariums may be useful in advancing conceptual knowledge about the night sky, because they afford learners with Earth-based views of celestial motions, give learners a sense of "being there," and allow direct observation of celestial motions. In this study, we asked whether a digital portable planetarium show would aid students in understanding celestial motions, as well as acquiring generalized astronomy-related knowledge. Results from our pre and post surveys suggest that students make gains in knowledge about both apparent celestial motion and general astronomy concepts after viewing a 25-minute planetarium presentation. Our results suggest that the portable planetarium may be a useful strategy in supporting learners as they struggle with reconciling observed patterns with underlying, non-observable motions of the Earth, and with visualizing concepts such as the speed of planetary orbits relative to their position with respect to the sun.
\end{abstract}

Keywords: Celestial Motion; Immersive Environments; Planetarium; Conceptual Knowledge

\section{INTRODUCTION}

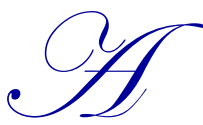

number of educational reform documents, from the 1996 National Science Education Standards (National Research Council, 1996) to today's Next Generation Science Standards (NGSS; National Research Council, 2012), emphasize that elementary students should learn about patterns that result from celestial motions, such as day and night, seasonal change of day length, and the different positions of the stars at different times. Such knowledge is fundamental not only to understanding the natural world, but can also provide an important route towards developing scientific habits of mind, such as using evidence to answer questions about the world around us. The NGSS are organized around several core disciplinary ideas which are thought to be fundamental to overall science literacy. By the end of $5^{\text {th }}$ grade, students should know that: "the orbits of Earth around the sun and of the moon around Earth, together with the rotation of Earth about an axis between its North and South poles, cause observable patterns. These include day and night; daily and seasonal changes in the length and direction of shadows; phases of the moon; and different positions of the sun, moon, and stars at different times of the day, month, and year." They should also know that: "Stars appear in patterns called constellations, which can be used for navigation and appear to move together across the sky because of Earth's rotation." (National Research Council, 2012).

Despite the longtime acknowledgement of, and current emphasis on, the importance of teaching and learning these concepts, instruction and learning in this area can be challenging. Students often hold deeply-rooted preconceptions about planetary motion and astronomy that are scientifically inaccurate, and traditional instruction is often unsuccessful in changing these conceptions (Plummer, 2009a; Treagust \& Duit, 2008). In a study of first, third, and eighth graders, Plummer (2009a) found that most students believed that the path of the sun across the sky is the same in summer and winter. Plummer also found that about $40 \%$ of $3^{\text {rd }}$ and $8^{\text {th }}$ grade students think that the 
stars do not change observed position. In a separate study, Sharp (1996) found that most $6^{\text {th }}$ grade students also believe that stars do not change observed position. Sharp also found that $43 \%$ of students did not attribute seasonal change to the Earth's tilt on its axis, but instead had a variety of conceptions for seasonal change, ranging from large changes in distance between the Earth and Sun in summer and winter, to Earth revolving very slowly on its axis to cause seasonal change. Trumper (2001) found that about half of the junior high students he studied believe that the seasons are caused by change in distance between the Earth and Sun.

Vosniadou and Brewer (1994) classified astronomy-related alternate conceptions as "intuitive," or based on everyday experiences and reasoning, or "synthetic," which are based on a blending of initial intuitive mental models with scientifically accepted explanations (Vosniadou \& Brewer, 1994). Synthetic models result when learners add on pieces of new information to a deeply held existing framework that may be difficult to abandon (Vosniadou, 2012). In order to change preconceptions to be consistent with scientifically accepted concepts, learners must be provided with experiences that can aid student comprehension, rather than simply being given new factual explanations (Bransford, Brown, \& Cocking, 2000; Vosniadou, 2010).

With respect to astronomy, it may be that these intuitive and synthetic conceptions develop in part due to lack of direct evidence to the contrary on the part of students (Plummer, 2009a). For instance, observing motions of the sun or stars takes time - unless a student stays out for hours at night observing the sky, or tracks the progress of the sun across the sky intentionally during the day, it can be difficult to observe these motions directly. In addition, tools often used in the classroom to present astronomy concepts do so from a perspective that is not consistent with how students would actually view the night sky. For instance, classroom models that use representations of the Earth and sun generally ask students to view the relative movements of these bodies from an external perspective, essentially from a vantage point of someone traveling in space. When Earth based, the models are rarely place specific, so patterns shown may be very different from what students can actually view from their location.

Planetarium experiences have the potential to change astronomy-related preconceptions by giving a learner the experience of viewing celestial motions directly. In particular, digital technology, found in both fixed and digital portable venues, can be used to simulate complex motions of objects in the sky. Time can be "sped up" in a planetarium, allowing learners to observe the changing positions of the stars throughout a simulated night, or the sun in a simulated day, thus obviating the need for a learner to directly observe the sky for long periods of time in order to detect a pattern. Learners also have the opportunity to hear verbal explanations that accompany these visual experiences in order to help make sense of what they are seeing. For instance, learners can see stars rotating around a stationary North Star over the course of several minutes. Because the observed pattern is that of stars moving, learners might not infer that it is actually the movement of the Earth that creates the apparent motion of the stars without hearing a verbal explanation.

Planetariums also have the potential to mediate learning by providing unusual and heightened sensory experiences that focus a learner's attention (Fraser et al., 2012). Immersive environments such as the planetarium give participants a sense of "being there," which is often referred to in the literature as "presence" (Barfield, Zelter, Sheridan, \& Slater, 1995; Jelfs \& Whitelock, 2000; Minsky, 1980; Yu, 2005). Immersive experiences with a strong sense of "presence" are positively correlated with attention (Darken, Bernatovich, Lawson, \& Peterson, 1999) and can result in conceptual change, in some cases (e.g. Limniou, Roberts, \& Papadopoulos, 2008; Sumners, Reiff, \& Weber, 2008). However, few studies have been published on the effectiveness of planetariums in advancing understanding of celestial motion (but see Bishop, 1980; Plummer, 2009b). As portable planetariums increasingly come into use, more research is needed to establish the learning value of these systems (Schnall, Hedge, \& Weaver, 2012). The present study asks whether viewing a portable planetarium show focused on apparent celestial motion, seasonal change of the sun's position, and planetary orbits can help students better understand celestial motion and other astronomy concepts. We hypothesized that the affordances of the planetarium, such as a strong sense of presence and the ability to simulate observable motion from a specific Earth-based perspective, would aid students in understanding celestial motions, as well as acquiring generalized astronomy-related knowledge. 


\section{METHODS}

\section{Study Site and Participants}

The study took place in a small city in Alaska. The nearest fixed planetarium is over 300 miles away from the study site, and there are limited opportunities for students to view the university-owned portable planetarium used in the study. We selected two schools with similar demographics for participation. All fourth-grade classrooms at both schools participated in the study. In total, 108 students (57 female, 51 male) from nine classrooms (some classrooms were multi-age and contained relatively few fourth graders) completed both the pre and post-tests (this total is lower than the total number of fourth graders in participating classrooms, due to absences on days that the pre and/or post tests were administered). We selected fourth grade in part because the local school district lists astronomy as part of the fourth grade curriculum; thus, there was incentive for teachers to participate in the intervention. However, we verified through teacher questionnaires that no content related to the learning goals of our intervention was taught in any participating classroom during the three weeks between the pre- and postsurveys.

\section{Planetarium Presentation}

The intervention was designed for, and delivered with, a digital STARLAB projection system, used in conjunction with a 6-meter diameter Digitalis ${ }^{\circledR}$ dome, which is hemispherical and fan-inflated. The digital STARLAB utilizes a DLP projector to produce a high-contrast image of the night sky 1080 pixels in diameter. The image is projected onto a dome using a specially designed fish-eye lens that minimizes distortion. The projection system is driven by the "small dome" version of Starry Night, an astronomy night-sky software program (Starry Night 6.3, Science First).

Educators from the University of Alaska Museum of the North gave an interactive, 25 minute long presentation to several groups of students. The same educator gave all of the presentations, while another individual assisted students in entering and exiting the planetarium. The presentations were given to all classes in a single school over two consecutive days. Presentations at school 1 were given one month prior to presentations at school 2. The presentation had four specific learning objectives related to Alaska's science performance standards and grade level expectations (which have since changed): 1) the apparent movements of objects in the night sky are observable and related to Earth's movements; 2) stars appear to rotate around the North Star; 3) the tilt of the earth on its axis affects the season and day length; and 4) like the Earth, other planets orbit the sun.

The presentation started with a display of the daytime sky as it would have appeared in Alaska (in the actual location of the study). After introductory material and orientation to compass points, zenith, and horizon, presenters displayed the path of the sun across the sky by speeding up time and showing a 24 hour path of the sun over the course of a couple of minutes. The presenter related this observed pattern back to the underlying phenomenon: that the Earth rotates on its axis, giving us day and night on Earth over 24 hours. Next, the presenter displayed the path of the sun across the sky during different seasons, and related the differing observed paths of the sun back to Earth's tilt on its axis. This explanation included a visual representation of Earth spinning on its axis. The presenter then switched to a night view of the sky. After some orientation to the Big Dipper (an asterism within Ursa Major) and its relationship to the North Star (Polaris), as well as inclusion of Alaska Native names and stories about the North Star, the presenter asked the students to focus on the North Star while time was sped up. The students were able to observe the majority of stars rotating around the night sky, while the North Star stayed still. The presenter related this back to the movement of the Earth and the North Star's unique position in the sky (directly above our axis). At this point, the presenter talked about constellations and included a number of Alaska Native stories about these constellations. Finally, a moving view of the Earth orbiting the sun, and then a view of other planets orbiting the sun, was presented, as well as an explanation that a planet's path around the sun was called an orbit, and that those planets closer to the sun orbit faster than those far away from the sun. The digital planetarium allows users to present views from multiple perspectives, such as showing the planet's orbits from above, in a way that earlier types of planetariums would not allow due to technological limitations. 


\section{Data Collection}

To assess the impact of the intervention in changing astronomy-related knowledge, we developed a written survey that focused on the main learning objectives of the presentation: 1) the apparent movements of objects in the night sky are observable and related to Earth's movements; 2) stars appear to rotate around the North Star; 3) the tilt of the Earth on its axis affects the season and day length; and 4) like the Earth, other planets orbit the sun. Knowledge items were drawn from published Alaska Standards Based Assessments of Science (State of Alaska, 2011). The survey contained eight knowledge questions, each with four possible answers.

To recruit participating classrooms, we presented the purpose of the intervention and study to teachers at staff meetings at each of the two target schools. Participating teachers (all fourth grade teachers at each school) distributed a pre-survey two weeks before the planetarium presentation, and distributed an identical post survey one week after students viewed the presentation ( 3 weeks total between pre and post surveys). Teachers agreed not to teach astronomy between the administration of the pre- and post- surveys. Students wrote a teacher-assigned code on their surveys to facilitate paired analysis of responses. Participating teachers received a $\$ 100$ stipend.

After the post-survey was administered, we also conducted interviews with a subset of students in order to gain more insight into how they thought that the planetarium changed their ideas about astronomy-related concepts. We randomly selected 20 students (4 or 5 from each $4^{\text {th }}$ grade classroom) from each school (40 total students) to participate in a 10 to 15 minute interview. Students were selected using the numbers assigned to them for the written pre/post-survey. Each interview lasted approximately 10 minutes. The interviewers were not previously known to the students. Multiple interviewers conducted the interviews. All received training and worked from a printed interview script. During interviews we asked students to explain how seeing the portable planetarium show helped them understand the various concepts covered by the planetarium show and tested on the pre/post-survey, using the following questions: 1) How did seeing the portable planetarium show help you understand how day and night occur on Earth? 2) How did seeing the portable planetarium show help you understand how planets orbit the sun? 3) How did seeing the portable planetarium show help you understand why the sun appears to move across the sky every day? 4) How did seeing the portable planetarium show help you understand why the days are shorter in the winter than in the summer? 5) How did seeing the portable planetarium show help you understand why the stars appear to move during the night? 6) How did seeing the portable planetarium show help you understand the North Star, Polaris? Interviews were audio recorded and transcribed.

\section{Data Analysis}

We scored the pre- and post-surveys and calculated the number of correct answers for the survey as a whole, as well as for each knowledge question. We then used a paired t-test (SPSS version 19) to test whether the difference between the pre and post-survey means were significantly different for the matched samples. We also conducted a univariate ANOVA to ask if there were differences in score changes (pre to post) between the two schools. With respect to coding interview responses, we defined four codes prior to analyzing the data: visual explanation, oral explanation, already knew the answer before seeing the planetarium presentation, or "other" (e.g. don't know, unrelated answer, no answer). Visual explanations were those where a student indicated that seeing something in the show furthered understanding, while oral explanations were those that indicated that something they heard during the presentation furthered understanding. Two coders independently assigned codes to phrases within interview responses. Inter-rater reliability was over $95 \%$.

\section{RESULTS}

The overall mean number of correct answers on the knowledge survey increased significantly $(t=-3.08$; df $=107 ; p=0.003$ ) from 4.66 on the pre-survey to 5.20 on the post-survey (out of 8 possible correct; Table 1). The effect sizes (Cohen's d) for the entire survey, as well as for all but one of the individual questions, fell between 0.2 and 0.3. These effect sizes are small to moderate (Cohen 2013), which reflects the fact that students increased their overall score by about one point between the pre and the post-test. There were no differences in pre to post-survey scores between the two schools studied $\left(F(1,107)=2.1, p=0.15, r^{2}=0.02\right)$. In terms of interview responses, the students frequently cited visual explanations $(44.3 \%)$, such as "it felt like you were actually looking at it when it was 
spinning," as being helpful in understanding concepts, while a lower percentage cited oral explanations as being helpful (7.1\%). A high number of responses (43.4\%) fell into the "don't know, no answer, or unrelated answer" category, and $5.2 \%$ stated that they knew the answer before viewing the planetarium show. Several students mentioned that the planetarium felt "real" or that it presented a "more realistic" viewpoint.

We present a question-by-question analysis below, dividing questions into two groups and including both quantitative and qualitative results. The "apparent motion" questions focused more on concepts related to apparent motion, while the "general knowledge" questions represent concepts about astronomy that were related to constellations or orbits.

Table 1. Paired t-test results for pre and post-survey items

\begin{tabular}{|c|c|c|c|c|c|c|c|c|}
\hline \multirow[b]{2}{*}{ Question } & \multicolumn{3}{|c|}{ Mean } & \multirow[b]{2}{*}{$\begin{array}{l}\text { Stand. } \\
\text { Dev. }\end{array}$} & \multirow[b]{2}{*}{$\begin{array}{c}\text { Cohen's } \\
\text { d }\end{array}$} & \multirow[b]{2}{*}{ t-value } & \multirow[b]{2}{*}{ df } & \multirow[b]{2}{*}{$\begin{array}{c}\text { p- } \\
\text { value }\end{array}$} \\
\hline & $\begin{array}{l}\text { Correct } \\
\text { Pre- }\end{array}$ & $\begin{array}{l}\text { Correct } \\
\text { Post- }\end{array}$ & Change & & & & & \\
\hline All questions & 4.66 & 5.20 & -0.55 & 1.84 & 0.3 & -3.08 & 107 & 0.003 \\
\hline \multicolumn{9}{|l|}{ Apparent motion questions } \\
\hline $\begin{array}{l}\text { Why does the Sun appear to } \\
\text { move across the sky every day? }\end{array}$ & 0.36 & 0.47 & -0.11 & 0.59 & 0.2 & -1.97 & 107 & 0.05 \\
\hline $\begin{array}{l}\text { Why do day and night occur on } \\
\text { Earth? }\end{array}$ & 0.58 & 0.43 & 0.15 & 0.61 & 0.2 & 2.53 & 106 & 0.01 \\
\hline $\begin{array}{l}\text { In Alaska there are fewer hours } \\
\text { of daylight in winter than in the } \\
\text { summer. Why? }\end{array}$ & 0.77 & 0.86 & -0.09 & 0.44 & 0.2 & -2.28 & 106 & 0.03 \\
\hline $\begin{array}{l}\text { Which statement best describes } \\
\text { why the star Polaris seems to } \\
\text { stay in one place while the other } \\
\text { stars seem to spin? }\end{array}$ & 0.64 & 0.74 & -0.11 & 0.50 & 0.2 & -2.24 & 104 & 0.03 \\
\hline $\begin{array}{l}\text { What is special about the star } \\
\text { Polaris? }\end{array}$ & 0.67 & 0.80 & -0.13 & 0.56 & 0.2 & -2.46 & 105 & 0.02 \\
\hline \multicolumn{9}{|l|}{ General astronomy questions } \\
\hline $\begin{array}{l}\text { The path a planet takes around } \\
\text { the sun is called... }\end{array}$ & 0.66 & 0.65 & 0.01 & 0.58 & 0.0 & 0.18 & 106 & 0.86 \\
\hline $\begin{array}{l}\text { Which statement is true about } \\
\text { the orbits of planets? }\end{array}$ & 0.63 & 0.76 & -0.14 & 0.52 & 0.3 & -2.73 & 106 & 0.008 \\
\hline $\begin{array}{l}\text { Which constellation is the Big } \\
\text { Dipper part of? }\end{array}$ & 0.39 & 0.53 & -0.14 & 0.56 & 0.3 & -2.54 & 101 & 0.01 \\
\hline
\end{tabular}

\section{Apparent Motion Questions}

1) Why does the sun appear to move across the sky every day?

The most frequent response to this on the pre-survey was "Earth orbits around the sun" (50.9\%), followed by the correct response "Earth rotates on its axis" (36.1\%). The frequencies shifted significantly on the post-survey $(t=-1.97 ; \mathrm{df}=107 ; p=0.05)$, with "Earth rotates on its axis" becoming the most frequent response $(47.2 \%)$. However, "Earth orbits around the sun" was still a very frequent response on the post-survey (44.4\%).

When students were asked about how the planetarium show helped them understand how the sun moves across the sky every day, almost $60 \%$ mentioned that a visual explanation was helpful. Quotes below are illustrative of the ways in which the planetarium may have been helpful in conceptual change around this idea:

"It helped me understand it because the - well, the Sun, when it's moving across the sky, I know it's actually us moving. So - oh, they showed - they told us that it's actually the Earth moving, and it showed them having the Sun go from east to west." (Student 21)

"Because it demonstrated that. It actually showed the sun rising in the east and setting in the west." (Student 3) 
"Because it kind of - um - he - it showed like the horizon and then it would show the sun coming up and across the sky and then it showed it coming down and it would get a little darker, but then sometimes it would come up again, get light, and then dark, then light, and then dark. And it felt like the sun was just, you know, like every day." (Student 8 )

The correct response "Earth rotates on its axis," was the most frequent response to this question on both the pre and the post-survey, but the number of correct answers decreased significantly $(t=2.53 ; \mathrm{df}=106 ; p=0.01)$ from pre- to post-survey ( $58.3 \%$ and $42.6 \%$, respectively). The second most popular choice on the pre- and postsurvey was "The Earth's axis is tilted" ( $25.0 \%$ and $34.3 \%$, respectively).

Despite the decrease in correct answers on the survey, a number of students stated that either an oral $(17.1 \%)$ or visual explanation $(34.3 \%)$ was helpful in understanding the concept when they were asked how the planetarium show helped them understand why day and night occur on Earth:

"It gave a picture of it and I could see the sun moving across the sky." (Student 15)

"Well, it really helped, because it looked - it felt like you were standing like on the northern side of the hemisphere and then the sun came and then it got dark and then it came and got dark. And it felt like, since it was also up, you know, like in a half-circle, it felt like you were actually looking at it when it was spinning." (Student 11)

"Because he was telling all about the Earth moving, the sun staying in one spot, all that." (Student 4)

In Alaska, there are more hours of daylight in winter than in summer. Why?

There was a very high level of pre-existing knowledge with respect to this question, as evidenced by the large number of correct responses (The Northern Hemisphere is tilted away from the sun in the winter) on the presurvey $(76.9 \%)$. Even so, the percentage of correct answers increased significantly on the post-survey, rising to $85.2 \%(t=-2.28 ; \mathrm{df}=106 ; p=0.03)$. Surprisingly, very few students $(7.4 \%$ on the pre-survey and $0.9 \%$ on the post survey) chose a generally common (e.g. Sharp 1996), though incorrect response: "The Northern Hemisphere is closer to the sun in the winter." Instead, the second most popular choice was "The sun moves below the horizon in summer" $(10.2 \%$ on the pre-survey and $9.3 \%$ on the post-survey).

In response to the related interview question, "how did seeing the portable planetarium show help you understand why the days are shorter in the winter than in the summer," students that gave related answers again often mentioned visual explanations (41.7\%). Quotes below are illustrative of how the intervention may have helped cement this concept:

"They showed us different seasons and in the summer it was lighter longer, and then in winter it was darker for longer." (Student 21)

"Because the sun is lower in the winter than in the summer." (Student 28)

"He used his computer and made it show up [the path of the sun] and he showed us." (Student 8)

4) Which statement best describes why the star Polaris seems to stay in one place while the other stars seem to spin?

Again, there was a relatively high level of pre-knowledge for this question, with $63 \%$ of students giving the correct answer, "Polaris is located almost exactly above the Earth's axis." The second most popular choice on the pre-survey was "Polaris's axis is tilted and it spins as it orbits the sun (14.8\%). On the post-survey, $74.1 \%$ of students chose the correct answer, a significant shift $(t=-2.24 ; \mathrm{df}=104 ; p=0.03)$. "Polaris's axis is tilted and it 
spins as it orbits the sun" remained the second most popular choice on the post-survey, although the number of students giving that answer dropped $(9.3 \%)$.

With respect to the related interview question, "how did seeing the portable planetarium show help you understand why the stars appear to move during the night," students that gave related answers again most often mentioned explanations that were visual in nature as being helpful (48.6\%):

"It just helped, since it was much easier to see than just going out every night and looking at the stars and recording how they moved in each particular position. It was sort of all in one as it was rotating." (Student 3)

"It showed the night sky and when it's spinning it seems like the stars are moving." (Student 11)

"It showed us, we rotated like - whee, only slower." (Student 26)

"By seeing the example of showing when the Earth turns it looks like the stars are moving." (Student 30)

What is special about the star Polaris?

Although the correct answer to this question was apparent-motion related, it differs from the preceding questions, as the phrasing of the question and the four possible answers were aimed at testing recall from the planetarium experience, rather than necessarily getting at an underlying conceptual understanding of celestial motion. A high number of students selected the correct answer, "Polaris appears to stay still in the sky when others move" on the pre-survey $(66.7 \%)$, and the number of students answering correctly rose significantly $(t=-2.46 ; \mathrm{df}=$ $105 ; p=0.02)$ on the post-survey $(78.7 \%)$.

During the interview, students were asked "how did the portable planetarium show help you understand the North Star, Polaris?" Answers were again mostly related to visual explanations when related to the question, including:

"It helped me understand it because it showed that all the stars were moving around but the North Star, Polaris, didn't move." (Student 7)

"You could actually see it and you're not just getting talked to." (Student 1)

"Because it would show all the stars spinning and then that one just staying still." (Student 6)

"It showed how it was above our axis." (Student 16)

\section{General Astronomy Questions}

1) The path a planet takes around the sun is called....

This was a simple vocabulary question, and there was no change between pre- and post-survey scores. Sixty-five percent of students responded correctly, "orbit," on both the pre- and post-survey, while the second most common response, "rotation," was selected by $16.7 \%$ of students on both the pre- and post-survey $(t=0.18$; $\mathrm{df}=$ $106 ; p=0.86$ ). No interview responses are relevant for this question.

Which statement is true about the orbits of planets?

The correct response, "planets closer to the sun orbit faster," was chosen by $61.2 \%$ of students on the presurvey, and by $75.0 \%$ of students on the post-survey, a significant shift $(t=-2.73 ; \mathrm{df}=106 ; p=0.008)$. All three of the other options, "planets further from the sun orbit faster," "planets complete their orbit in one month," and "planets orbit other planets," were equally selected on the pre-survey ( $12 \%$ each, with $2.8 \%$ answers missing). On 
the post-survey, answers to the other three options were still fairly equally distributed $(8.3 \% ; 6.5 \%$, and $9.3 \%$ respectively).

When asked "how did seeing the portable planetarium help you understand how planets orbit the sun," students again responded with answers that were mostly visual explanations $(41.7 \%)$, or gave unrelated answers. Responses that gave visual explanations included:

"Well it presented itself in a more neat fashion, since they're - the orbits of the planets are usually jumbled up in pictures I see in books...." (Student 2)

"Because at one point it showed the diagram and then it showed like all of the planets going around each other and so it showed you how the planets circle around the sun. It showed you like the inner planets and the outer planets." (Student 10)

"Well, in one part of it they had the Sun and these little lines with the planets around it, and they named them and they just go around and around." (Student 26)

"Well, there was like - like when we looked in the planets, the inner planets were rotating very fast." (Student 33)

3) Which constellation is the Big Dipper part of?

Again, this question was aimed more at recall, since a fair amount of time was spent during the planetarium presentation on Polaris, the Big Dipper and its role as an asterism. On the pre-survey, $38 \%$ of students responded correctly that the Big Dipper was part of Ursa Major, while on the post-survey, this number rose significantly to $51.9 \%(t=-2.54 ; \mathrm{df}=101 ; p=0.01)$. No interview responses were relevant for this question.

\section{DISCUSSION}

Our study set out to examine whether or the digital portable planetarium, which affords a strong sense of presence and the ability to simulate observable motion from an Earth-based perspective, could aid students in understanding celestial motions, as well as acquiring generalized astronomy-related knowledge. Overall, students in our study did demonstrate statistically significant gains in astronomy-related knowledge after viewing the planetarium presentation, both with respect to concepts related to apparent celestial motion and with respect to more generalized knowledge.

With respect to knowledge about apparent celestial motion, we saw positive shifts in answers to all of the questions except one: why do day and night occur on Earth, which had a negative shift. This creates a bit of a paradox: while more students were able to link Earth rotating on its axis with the apparent movement of the sun across the sky after viewing the planetarium presentation, it appears that fewer were able to link this rotation with day/night cycles. The differences in responses to this question and the previous question might indicate that 1) these two processes were somehow not linked in the students' minds; 2) the survey question was not well understood, despite the fact that we used validated, published questions; 3) something in the presentation was confusing; or 4) that students were confused by the fact that there were two different questions that had the same correct answer. Students may have assumed that the same answer could not apply to two different questions, even if they understood the phenomenon, and this may have led them to choose an alternate answer.

Despite the decrease in correct answers associated with the day/night cycle, students overall did increase their knowledge about celestial motions after viewing the planetarium presentation. The marked increase in knowledge gains about the reason for the seasons, as well as the positive increases in correct responses to our two questions about the apparent motions of the stars, indicates that the planetarium presentation aided students in linking visual observations with those movements. We also saw increases in numbers of correct answers to our general knowledge questions - those about planetary orbits and constellations. Overall, these results suggest that the digital planetarium format has the potential to positively impact student knowledge about astronomy, particularly 
with respect to concepts that can be difficult to master through traditional instruction. It appears that the visual nature of the planetarium may be responsible for much of this impact. During interviews, students often referred to visualizations that are only possible with the affordances of a digital system, such as the ability to speed up time.

With respect to pre-intervention conceptions, a surprisingly large number of students held synthetic and scientific models prior to planetarium instruction. For instance, the idea that the Earth rotates around the Sun to make the sun appear to move across the sky everyday does involve a layered mental model consisting of several scientifically correct conceptions: 1) the Earth is a sphere; 2) the sun is stationary, and 3) the Earth revolves around the sun (Vosniadou \& Brewer, 1994). It appears that students that related Earth's rotation around the sun to day and night still hold misconceptions about: 1) the length of time it takes for the Earth to travel around the sun, 2) Earth's rotation about its axis, or 3) both. It may be that these students had previous instruction in astronomy prior to our study. Several students mentioned learning concepts the year before or that they "already knew" some of the material presented. Our findings stand in contrast to those of Plummer (2009a), who found that student conceptions of celestial motion at the $8^{\text {th }}$ grade level were not strikingly different from those of $3^{\text {rd }}$ graders, despite presumed instruction prior to $8^{\text {th }}$ grade in these areas. One reason for this discrepancy, at least in some conceptual areas, could be that in the study's location, there is extreme variation in day length between winter and summer, and presumably students have more opportunities to observe seasonal differences in daylight. However, the underlying explanation cannot be acquired through direct observation, so prior knowledge of why the daylight hours differ must have been a result of prior explanations, possibly paired with observations.

Our results with respect to knowledge increases are consistent with previous studies (Bishop, 1980; Plummer, 2009b). Plummer (2009b) attributed gains in knowledge to a combination of kinesthetic and visual elements in her planetarium intervention. She suggests that Dual Coding Theory (Clark \& Paivio, 1991, within Plummer, 2009b) accounts for separate and cumulative processing of verbal, visual, and kinesthetic elements to create a powerful learning experience that can aid in changing conceptions about celestial motion. Our study suggests that the planetarium may afford a rich learning environment even in the absence of kinesthetic elements.

While our study overall shows that the digital portable planetarium has the potential to increase knowledge about astronomy, there are some limitations to our inferences. Because we used a pre-post design with no control, it is possible that our study could be subject to internal validity threats. One such threat is a testing effect, or that students may have done better on the post-test due to simply taking the pre-test. Although it is possible, we find this unlikely. Students did not receive their score after taking the first test, and thus had no way of knowing what answers were correct or incorrect, or if personal improvement could be made. We feel that this makes it less likely that simply taking the pre-test would impact post-test scores. The biggest validity threat with respect to this study is the possibility that students gained astronomy knowledge from an external source between pre and post-testing. While we cannot rule out the possibility of exposure to astronomy concepts other than through the intervention between the pre- and post-survey, we did use strategies to help limit exposure, including asking teachers not to cover intervention-related material during that time period, verifying with teachers that this did not occur, and limiting the length of the time period between administering the pre and post-survey ( 3 weeks, with the intervention occurring one week after the pre-survey and the post-survey occurring two weeks after the intervention). The interview results, in which students reported ways in which the planetarium helped them understand concepts, are also indicative of intervention impact.

\section{CONCLUSION}

There is considerable interest in the impacts of immersive environments on learning among the educational community, both in formal and informal learning contexts. While the literature suggests that immersive environments can positively impact learning, evidence for impacts on memory and performance are limited (Schnall et al., 2012). We demonstrate here that the digital portable planetarium can help learners gain new astronomyrelated knowledge, possibly because it affords learners Earth-based viewpoints that allow for observation of celestial motions over shortened periods of time, and because it makes the experience seem "real." To the extent that these results are generalizable, they suggest that viewing a digital planetarium show may help support learners as they struggle with reconciling observed patterns with underlying, non-observable motions of the Earth, and with visualizing concepts such as the speed of planetary orbits relative to their position with respect to the sun. 


\section{ACKNOWLEDGEMENTS}

This work was supported by a grant from the National Aeronautics and Space Administration (NASA) under award number NNX09AD50G. We thank Chris Cannon for his work in presenting planetarium shows to students, as well as the cooperating teachers for allowing us to conduct the study in their classrooms. We also thank the two anonymous reviewers whose comments greatly improved the manuscript.

\section{AUTHOR INFORMATION}

Laura D. Carsten Conner is a Research Assistant Professor of Science Education at the College of Natural Science and Mathematics and the Geophysical Institute at the University of Alaska Fairbanks. She was formerly the Head of Public Programs at the University of Alaska Museum of the North.

Angela M. Larson is the owner and principal consultant of the Goldstream Group in Fairbanks, Alaska. She has more than 15 years of experience in program evaluation and specializes in the evaluation of community and educational programs.

Jennifer Arseneau is the Manager of Education and Public Programs at the University of Alaska Museum of the North. As an informal educator, she has worked in a variety of settings including national parks and museums. She served as the lead educator for this project.

Robert R. Herrick is a Research Professor at the Geophysical Institute at the University of Alaska Fairbanks who specializes in planetary geosciences. He has over 20 years of experience conducting educational outreach in planetary science and astronomy.

\section{REFERENCES}

Barfield, W., Zelter, D., Sheridan, T., \& and Slater, M. (1995). Presence and performance within virtual environments. In W. Barfield \& T.A. Furness III (Eds.), Virtual Environments and Advanced Interface Design (pp. 473-513). New York: Oxford University Press.

Baxter, J. H. (1989). Children's understanding of familiar astronomical events. International Journal of Science Education, 11, 502-513.

Bishop, J.E. (1980). The development and testing of a participatory planetarium unit emphasizing projective astronomy concepts and utilizing the Karplus learning cycle, student model manipulation, and student drawing with eighth grade students. PhD dissertation, The University of Akron.

Bransford, J. D., Brown, A. L., \& Cocking, R. R. (2000). How People Learn: Brain, Mind, Experience, and School: Expanded Edition. Washington, DC: The National Academies Press.

Clark, J.M. \& Paivio, A. (1991). Dual coding theory and education. Educational Psychology Review, 3, 149-210.

Cohen, J. (2013). Statistical power analysis for the behavioral sciences $\left(2^{\text {nd }}\right.$ Ed.). Hillsdale, New Jersey: Erlbaum.

Darken, R.P., Bernatovich, D., Lawson, J.P., \& Peterson, B. (1999). Quantitative measures of presence in virtual environments: The roles of attention and spatial comprehension. CyberPsychology \& Behavior, 2(4), 337347.

Fraser, J., Heimlich, J.E., Jacobsen, J., Yocco, V., Sickler, J., Kisiel, J., Nucci, M., Jones, L.F. \& Stahl, J. (2012). Giant screen film and science learning in museums. Museum Management and Curatorship, 27(2), 179195.

George, D. \& Mallery, P. (2003). SPSS for Windows step by step: A simple guide and reference. 11.0 update. $4^{\text {th }}$ edition. Boston: Allyn and Bacon.

Jelfs, A., \& Whitelock, D. (2000). The notion of presence in virtual learning environments: what makes the environment "real." British Journal of Educational Technology, 31, 145-152.

Limniou, M., Roberts, D., \& Papadopoulos, N., (2008). Full immersive virtual environment CAVE in chemistry education. Computers and Education, 51, 584-593.

Minsky, M., (1980). Telepresence. Omni, pp. 4552. 
National Center for Education Statistics (2011-2012).

http://nces.ed.gov/ccd/schoolsearch/school detail.asp?Search=1\&DistrictID=0200600\&SchoolPageNum=2 $\& \mathrm{ID}=020060000516$.

National Research Council. (1996). National science education standards. Washington, DC: National Academy Press.

National Research Council. (2012). A Framework for K-12 Science Education: Practices, Crosscutting Concepts, and Core Ideas. Committee on a Conceptual Framework for New K-12 Science Education Standards. Board on Science Education, Division of Behavioral and Social Sciences and Education. Washington, DC: The National Academies Press.

Plummer, J. (2009a). A cross-age study of children's knowledge of apparent celestial motion. International Journal of Science Education, 31, 1571-1605.

Plummer, J. (2009b). Early elementary students' development of astronomy concepts in the planetarium. Journal of Research in Science Teaching, 46, 192-209.

Schnall, S., Hedge, C., \& Weaver, R. (2012). The Immersive Virtual Environment of the digital fulldome: Considerations of relevant psychological processes. International Journal of Human-Computer Studies, 70, 561-575.

Sharp, J. G. (1996). Children's astronomical beliefs: A preliminary study of year 6 children in southwest England. International Journal of Science Education, 18, 685-712.

State of Alaska Department of Education and Early Development (2011). Alaska Science Assessment Practice Tests. Grade level 4. http://www.eed.state.ak.us/tls/assessment/SBA PracticeTests.html .

Sumners, C., Reiff, P., \& Weber, W. (2008). Learning in an immersive digital theater. Advances in Space Research, 42, 1848-54.

Treagust, D.F., \& Duit, R. (2008). Conceptual change: A discussion of theoretical, methodological and practical challenges for science education. Cultural Studies of Science Education, 3, 297-328.

Trochim, W. (2006). Research Methods Knowledge Base. Web Center for Social Research Methods. Retrieved from: http://www.socialresearchmethods.net/.

Trumper, R. (2001). A cross-age study of junior high school students' conceptions of basic astronomy concepts. International Journal of Science Education, 23, 1111-1123.

Yu, K.C. (2005). Digital Full-Domes: The future of virtual astronomy education. Planetarian, 34, 6-11.

Vosniadou, S. (2010). Reframing the Classical Approach to Conceptual Change: Preconceptions, Misconceptions and Synthetic Models. In B.J. Frazer, K. Tobin, \& C.J. McRobbie (Eds), The Second International Handbook of Science Education (pp. 119-130). Netherlands: Springer.

Vosniadou, S., \& Brewer, W. F. (1994). Mental models of the day/night cycle. Cognitive Science, 18, 123-183. 


\section{NOTES}

